\title{
Fetus in fetu: is it a baby inside a baby?
}

\begin{abstract}
Fetus in Fetu is a rare congenital anomaly in which monozygotic twin is incorporated into its sibling during development. It is a lesser known disease even in the medical community as less than 200 cases have been reported. Some theories have been proposed regarding the pathogenesis of fetus in fetu and clinical manifestations of fetus in fetu vary. It should be differentiated from teratoma which has no axial arrangement and has got definite malignant potential. Herein, we describe a 5month old boy with an abdominal mass. After ultrasound and CT scan, provisional diagnosis of Fetus in fetu causing bilateral moderate hydroureteronephrosis was made. Elective laparotomy revealed a well encapsulated retroperitoneal mass which was successfully excised. Complete excision of fetus in fetu is curative. The rarity of this case is the reason why we deem our case reporting.
\end{abstract}

Keywords: abdominal mass,amniotic sac, fetus in fetu,teratoma, twin

\author{
Volume 8 Issue I - 2018 \\ Susankar Kumar Mondal,' Abu Bakar \\ Akan, ${ }^{2}$ Mridul Prasad Joshi, ${ }^{3}$ Shamsul Huda, ${ }^{3}$ \\ Mahabub Hossain ${ }^{3}$ \\ 'Associate Professor, Department of Pediatric Surgery, \\ Bangabandhu Sheikh Mujib Medical University, Bangladesh \\ ${ }^{2}$ Assistant Professor, Department of Pediatric Surgery, \\ Bangabandhu Sheikh Mujib Medical University, Bangladesh \\ ${ }^{3}$ Resident, Department of Pediatric Surgery, Bangabandhu Sheikh \\ Mujib Medical University, Bangladesh
}

\author{
Correspondence: Susankar Kumar Mondal, Associate \\ Professor, Department of Pediatric Surgery, Bangabandhu Sheikh \\ Mujib Medical University, Bangladesh, \\ Email dr.sankar7ı@gmail.com
}

Received: November 14, 2017| Published: January 23, 2018

\section{Introduction}

Fetus in fetu is a rare congenital anomaly in which malformed fetus grows within the body of its twin. It is a rare case of abdominal mass. It is usually retroperitoneal or intraperitoneal but may also be present in scrotum or in cranial cavity. ${ }^{1}$ Several theories have been given regarding the pathogenesis. One such theory explains the pathogenesis of fetus in fetu as 'included twin theory' in which the fetus in fetu represents an aberration of monochorionic diamniotic monozygotic twinning in which unequal division of the totipotent inner cell mass of the developing blastocyst leads to the inclusion of smaller cell mass within a maturing sister embryo due to persistent anastomosis of vitelline circulation. So the fetus is surrounded by a membrane analogous to amniotic sac and supplied by a single feeding vessel. A true placenta is usually absent.

Another theory considers the fetus in fetu as highly differentiated mature teratoma. ${ }^{2-4}$ However, some literature suggest it can be differentiated from teratoma by the presence of vertebral organization with limb buds and other organ systems. ${ }^{5}$ Also the fetus in fetu is a benign disorder whereas the teratoma bears malignant potential. ${ }^{6}$ Thepresent study is an effort to present a rare case of fetus in fetu with review of available literature.

\section{Case report}

A 5 month old boy was admitted to Department of Pediatric Surgery, BSMMU on May 2017. At the age of 1 and half months, his parents noticed a lump in hislower abdomen. The lump is gradually increasing in size and is not painful. The boy has occasional vomiting but no other complains. The mother wasn't on regular antenatal checkup however there was no history of any maternal illness, exposure to radiation or drug intake during pregnancy. There was no family history of multiple pregnancies. The boy was delivered by cesarean section as he was postdated. His postnatal period was uneventful. On clinical examination, there was a $10 \times 10 \mathrm{~cm}$, well-defined, firm, non-tender, round mass occupying the right lumbar region, right iliac fossa, umbilical, hypogastric region and left iliac fossa. Laboratory investigations were within reference ranges. Alpha-feto protein was $36.25 \mathrm{ng} / \mathrm{ml}$ (up to $15 \mathrm{ng} / \mathrm{ml}$ ) and beta-HCG was $0.34 \mathrm{mIU} / \mathrm{ml}$ (within normal range). Ultrasound of abdomen showed a large complex mass having solid, cystic components located on the lower abdomen. It measures about $10.6 \times 9.0 \mathrm{~cm}$. the mass is separated from right kidney. Also, in kidney, pelvicalyceal system are moderately dilated but cortex medulla are well defined. CT scan reported one fetus measuring about $12 \times 11 \mathrm{~cm}$ is noted in the pelvic cavity and right lumber region having deformed skeleton within. The lesion is displacing the bowel, bladder and compresses the kidneys and ureters posteriorly. CT scan also reported moderate hydroureteronephrosis. A preoperative diagnosis of fetus in fetu with moderate hydroureteronephrosis was made (Figure $1 \&$ Figure 2).

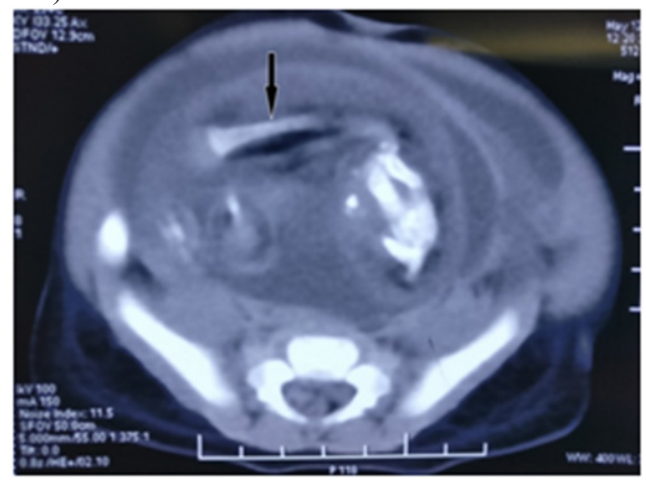

Figure I CT scan of the patient's abdomen reveals a large retroperitoneal soft tissue mass. There are long hypodense opacities that resemble fetal bones (see arrows).

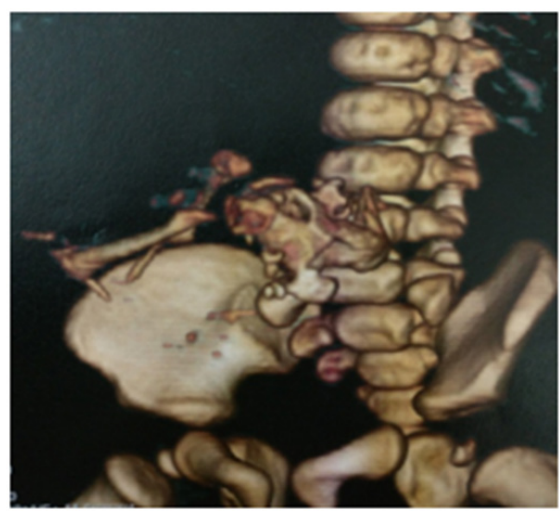

Figure 2 CT scan 3D Imaging of the patient's showing the skeleton components of the fetus. 
Parents were counselled for surgery and elective laparotomy was performed. We found a large retroperitoneal cystic mass displacing the bladder anteriorly and gut laterally. Dilated ureters were present on posterolateral aspect of the mass. The bladder was dissected free from the mass and the cystic component of mass was decompressed and the fetus removed after ligation and sectioning of the cord and the membrane also removed after dissection.

Macroscopic Examination revealed a soft tissue resembling a fetus, attached to the membranous sac via cord like structure. The mass weighed $250 \mathrm{gm}$ and measured $10 \mathrm{x} 8 \mathrm{~cm}$. Fetus was anencephalic and was covered entirely with intact skin except at the raw area at cephalic end. Vertebral column was palpable and presence of bilateral, symmetrical, well developed lower limbs with structures resembling toes were noted. Upper limbs were also present, but were rudimentary (Figures 3-6).

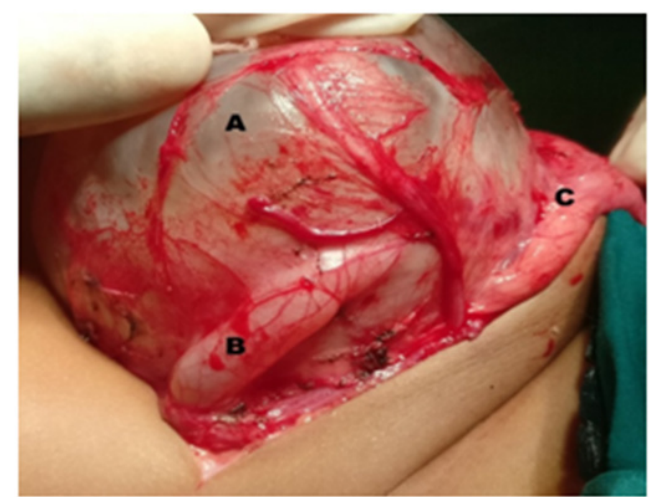

Figure 3 Membrane covering the fetus(A), Right ureter(B), Bladder(C).

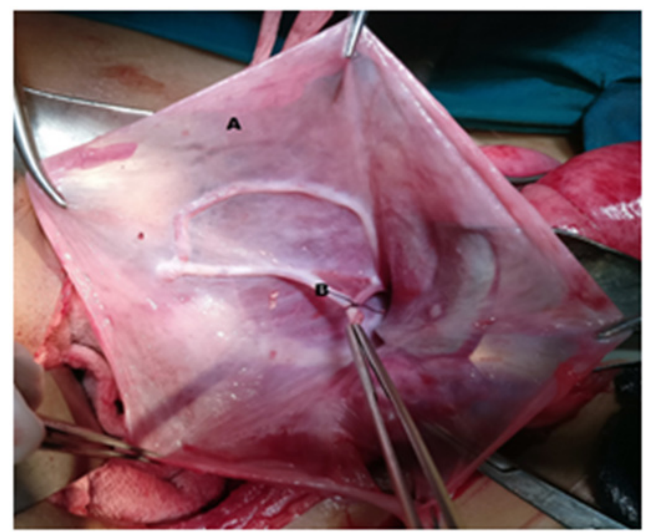

Figure 4 Opened sac showing inner surface(A), Umbilical cord of the fetus(B).

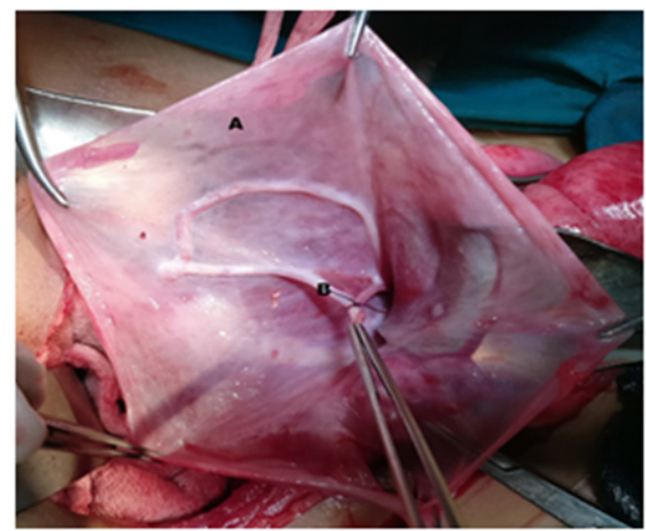

Figure 5 Postoperative specimen showing Lower limbs(A), Hair(B), Raw Area devoid of Skin(C).

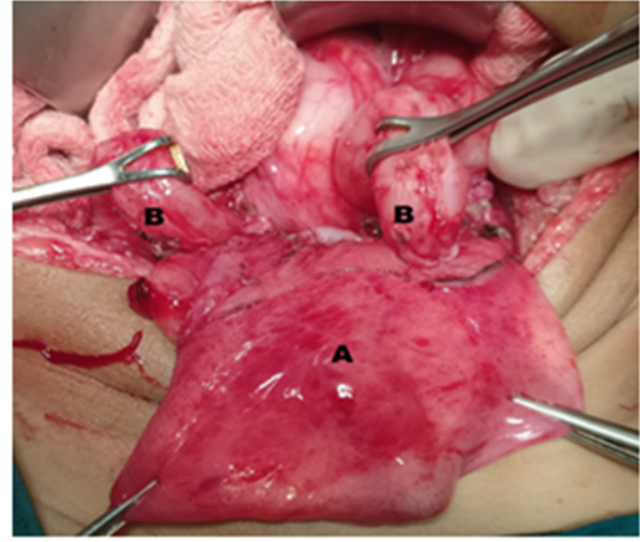

Figure 6 Peroperative figure showing Bladder(A), Hairs(B), Skin devoid raw area(C)Both ureters(B).

\section{Discussion}

Meckel in early 19th century coined the term 'fetus in fetu'. It is extremely rare pathology with incidence of 1 in 500,000 live births and less than 200 cases reported. ${ }^{6,7}$ First case was reported by George William Young in $1808^{8}$. According to the earlier definition proposed by Willis, ${ }^{9}$ Fetus in fetu was defined as 'presence of axial skeleton with vertebral axis with appropriate arrangement of other limbs and organs with respect to axis '. According to another definition proposed by Gonzalez-Crussi, ${ }^{5}$ FIF is applied to 'any structure in which the fetal form is in a very high development of organogenesis and to the presence of vertebral axes.' Later Federici et al., ${ }^{10}$ proposed that in the presence of structure with an advanced grade of fetal organization such as eyes, parts of central nervous system, well developed limb like processes, skin and colon, the diagnosis of FIF can be applied even in the absence of axial skeleton. Thakral et al., ${ }^{11}$ reported equal male and female predisposition but Patankar et al., ${ }^{12}$ and Federici et al., ${ }^{10}$ noted 2:1 male predominance.

During fetal development, vitelline circulation anastomoses cause a 'twin to twin transfusion' syndrome from the non-dominant to the dominant twin, resulting in impaired growth of the fetus, which progressively embeds itself within its twin sibling during the third week of gestation. The evolution of the twin fetus arrests at the first trimester. Different organs can be seen in fetus in fetu including vertebral column(91\%), $\operatorname{limbs}(82.5 \%), \operatorname{CNS}(55.8 \%), \operatorname{GIT}(45 \%)$, vessels $(40 \%)$, and genitourinary $(26.5 \%) .{ }^{13}$

To qualify as an FIF, one of the following characteristics must be present: a mass enclosed within a distinct sac, partially or completed covered by skin, grossly recognizable anatomic features and attached to the host by a pedicle containing a few relatively large blood vessels. ${ }^{14}$ In most cases, there is a single parasitic twin but rarely, more than 1 parasitic twin is observed in the host body. ${ }^{15}$ Studies of genetic markers, such as blood group, sex chromosome constitution, protein polymorphisms and DNA marker, suggested that host infants and their fetiform mass are genetically identical.

Most FIF are located retroperitoneally along the ventral midline and presents as abdominal mass, while other rare reported sited include the cerebral ventricles, liver, pelvis, scrotum and mediastinum. Patient with fetus in fetu commonly presents with abdominal mass. However symptoms of FIF relate mainly to its mass effect and include abdominal distension, feeding difficulty, emesis, jaundice, pressure effects on renal system such as hydroureteronephrosis in this case and dyspnea. ${ }^{10,13,16,17}$ 
Preoperative diagnosis is possible with computed tomography and pre- or postnatal ultrasonography. Plain abdominal X-ray may be helpful in diagnosis. In half of the cases, X-ray shows the vertebral column and axial skeleton. ${ }^{18}$

There is controversy as to whether FIF is a distinct entity or represents a highly organized teratoma. The main diagnostic challenge lies in differentiating this entity from immature teratoma with its associated risk of malignancy. A teratoma is defined as disorganized array of pluripotent cells, representing all three germ layers, that, unlike FIF, does not develop past the primitive streak stage (days 12 to 15). It is important to differentiate between teratomas and FIF because the former has $10 \%$ malignancy rate. In contrast, FIF is always benign. Clinically, FIF can be differentiated from teratoma by the presence of vertebral bodies and limbs, teratoma consists of pluripotent cells, without organogenesis or vertebral segmentation. Occasional cases of FIF have been reported in which spinal column could not be identified at imaging. These cases probably were due to an underdeveloped and markedly dysplastic spinal column that prevented the identification of vertebral bodies at imaging. ${ }^{19}$

Treatment of fetus in fetu is essentially surgical and complete excision of mass with surrounding membrane gives complete recovery. ${ }^{10}$ Careful dissection should be done to avoid injury to surrounding structures. In our case, we completely resected the mass with no subsequent complication to the best of our knowledge. Postoperatively the patient should be followedup with sonography and tumor markers (alpha-fetoprotein and beta-hcg).

\section{Conclusion}

Fetus in fetu is a rare and interesting entity that typically presents as an abdominal mass in infancy or early childhood. Though a rare entity, it should be kept in mind as a differential diagnosis for lump in abdomen in infancy and early childhood and should be well differentiated from teratoma which is a common variant.Complete excision is curative and confirmatory.

\section{Acknowledgments}

None.

\section{Conflicts of interest}

None.

\section{Funding}

None.

\section{References}

1. Suttiwan P, Sutthiwan I, Tree-traken T. Fetus in fetu. $J$ Pediatr Surg. 1983;8(3):290-292.
2. Eng HL, Chuang JH, Lee TY, et al. Fetus in fetu: a case report and review of literature. J Pediatr Surg. 1989;24(3):296-299.

3. Bader I, Akhter N, Sajjad M, et al. Twin fetus in fetu-a very rare enity: a case report with review literature. Pak J Med Sci. 2003;19:306-309.

4. Gangopadhyay AN, Srivastava A, Srivastava P, et al. Twin fetus in fetu in a child: a case report and review of the literature. J Med Case Reps. 2010;4:96.

5. Gonzalez-Crussi F. Extragonadalteratomas. Atlas of tumor Pathology. 2nd ser, fasc18. Armed forces institute of pathology, Washington DC, USA. 1982.

6. Hopkins KL, Dickson PK, Ball TI, et al. Fetus in fetu with malignant recurrence. J Pediatr Surg. 1997;32:1476-1479.

7. Arlikar JD, Mane SB, Dhende NP, et al. Fetus in fetu: two case reports and review of literature. Pediatr Surg Int. 2009;25(3):289-292.

8. Young GW. Case of fetus found in the abdomen of a boy. Med Chir Trans. 1809;1:234

9. Willis RA. The borderland of embryology and pathology, (2nd edn), Butterworths, Washington DC, USA. 1962. p.442-446.

10. Federici S, Ceccarelli PL, Ferrari M, et al. Fetus in Fetu: report of three cases and review of literature. Pediatr Surg Int. 1991;6:60-65.

11. Thakral CL, Maji DC, Sajwani MJ. Fetus in fetu: a case report and review of the literature. J Pediatr Surg. 1998;33(9):1432-1434.

12. Patankar T, Fatterpekar GM, Prasad S, et al. Fetus in fetu: Ct appearancereport of two cases. Radiology. 2000;214(3):735-737.

13. Hoeffel CC, Nguyen KQ, Phan HT. Fetus -in-fetu: a case report and literature review. Pediatrics. 2000;105(6):1335-1344.

14. Brand A, Alves MC, Saraiva C, et al. Fetus in fetu-diagnostic criteria and differential diagnosis-a case report and literature review. J Pediatr Surg. 2004;39(4):616-618

15. Kimmel DL, Moyer EK, Peale AR, et al. A cerebral tumor containing five human fetuses. A case of fetus-in-fetu. Anat Rec. 1950;106(2):141158.

16. Lewis RH. Foetus in foetu and retroperitoneal tratoma. Arch Dis Child. 1960;36:220-226.

17. Dagradi AD, Mangiante GL. Serio GF, Musajo FG, Menestrina FV. Fetus-in-fetu removal in a 47 year old man. Surgery. 1992;112(3):598692.

18. Khalifa NM, Maximous DW, ABD-Elsayed AA. Fetus in fetu: a case report. J Med Case Reports. 2008;10(2):2.

19. Nocera RM, Davis M, Hayden CK, et al. Fetus in fetu. Am J Roentgenol. 1982;138(4):762-764 